\title{
University and a non-profit organization activities for social adaptation of disabled people
}

\author{
Svetlana Sergeeva ${ }^{1}$, Olga Vagaeva $^{1}$, Diana Efimova ${ }^{1}$, Nadiia Galimullina ${ }^{2, *}$, and Alexander \\ Lushnikov $^{3}$ \\ ${ }^{1}$ Penza State Technological University, pr. Baydukova / Gagarina Str., 1a / 11, 440039 Penza, Russia \\ ${ }^{2}$ Kazan National Research Technical University named after A.N. Tupolev-KAI, Karl Marx Str., 10, \\ 420111 Kazan, Russia \\ ${ }^{3}$ Educational center, Autonomous Non-Profit Organization "Kvartal Lui”, Berezovsky lane, 19, \\ 440052 Penza, Russia
}

\begin{abstract}
The article views the issue of interaction between a university and an inclusive practices site for social adaptation of disabled young people. The following methods were used: analysis and synthesis, observation, interviews, and polling. The authors come to the conclusion that the results echo numerous works of other researchers. In this regard, it is essential to lay a fundamental basis of the inclusive world, which is possible under the following conditions: building a dialogue; competence of the subjects participating in the problem solving; systemic character of education and training. The research resulted in the designed program of partner interaction. To achieve the best possible results, it implies its stageby-stage, systemic and comprehensive implementation in educational and cultural-leisure spheres, encompassing various aspects of social rehabilitation (social-environmental, social-psychological, socialpedagogical, socio-cultural, social-communal adaptation).
\end{abstract}

\section{Introduction}

An important task for the social development of the Russian Federation is work with the disabled. Its topicality for the Russian society is proclaimed in the Federal Law "On social protection of the disabled in the Russian Federation" of 24 November 1995 No. 181-FZ (last modified 1 January 2020), which stipulates obtaining education by the disabled and guarantees provision of favorable conditions for obtaining education. According to the Law, this support consists in implementation of their rights and freedoms alongside with other members of the society; in development of a personality as social subject, its individual potential and development trajectory; integration into the public environment.

Obtaining education by the disabled may be implemented at various levels of comprehensive and free of charge pre-school, primary school, basic, secondary basic and

* Corresponding author: ngalimullina@gmail.com 
secondary professional education, as well as free of charge higher education. Today, due to modernization of the structure educational programs, the disabled may be provided with special and necessary conditions of obtaining education according to adapted programs of flexible and effective character. Within these programs, the disabled young people may master new competences along flexible learning trajectories if various inclusive practices sites actively cooperate with universities. It becomes possible under the constantly improving system of modern continuous education in compliance with the established prospects for long-term social-economic development of the Russian Federation for the period up to 2030. For example, since 2010, Kazan National Research Technical University named after A.N. Tupolev - KAI runs the Kazan Academic-Research and Methodology Center for professional rehabilitation of the people with disabilities and health limitations as an inclusive education site for the people with health limitations, deaf, hard of hearing and visually impaired people.

In the recent years, the interest has increased towards the problem of life-long learning of the disabled in general and using inclusive practices for training and social adaptation of the young disabled people. A review of research in this sphere up to 2001 was compiled by E. Avramidis and B. Norwich [1]. Generally, the research showed that there are positive changes concerning inclusion introduction, but complete inclusion has not occurred yet. The article of 2020 [2] presents the results of thematic analysis of 26 reviews on the topic of inclusion in education, covering the attitude towards inclusion in education on the part of the educational process participants and the society as a whole, the professional development of the teachers and their preparedness for inclusion. In most of the works, the topic of evolution of approaches towards education of people with special needs is touched upon; further, the researchers complement their works with the analysis of the "inclusion" notion from the viewpoint of human rights [3], the review of the modern stage of solving the problem [4]. Many works analyze the features of introducing inclusion into the educational systems of various regions [5-6].

When summarizing the practice of inclusive education in Russia, the Russian scholars emphasize the key obligations of the state towards learners with disabilities, which are reflected in the current state policy in the sphere of providing inclusion in higher education [7]. A. V. Bakharev studied the genesis of inclusive education in Russia and estimated the implementation of inclusive educational practices in the context of legal regulation of the issue [8]. Many researchers highlight the poor practical elaboration of the conditions (material-technical, organizational, educational-methodological, personnel) of the inclusive education development in modern Russia.

Undoubtedly, to achieve inclusion in education it may be insufficient to apply a "downward" approach (under the influence of the national and international policy and the human rights policy), as the inclusion process also work at the level of everyday social interaction, where politics is less important [9].

Analysis of various scientific works allows concluding that the issue of potential directions and forms of interaction between a university and an organization engaged in the social adaptation of young disabled people remains poorly researched in the scientific pedagogical literature.

\section{Materials and methods}

While the issue of inclusive education is still at the stage of scientific comprehension and the ways and mechanisms of its practical solution are being searched for, it is important to render targeted assistance in solving the specific tasks emerging before the organizations engaged in the social adaptation of young disabled people. 
In the light of the above, the objective of the present work is to define and substantiate the directions and forms of partner interaction of a university - Federal State Budget Higher Educational Establishment Penza State Technological University and a pilot multifunctional inclusive practices site for social adaptation of disabled young people by the example of the autonomous non-profit organization "Kvartal Lui".

To solve the set task, both theoretical and empirical methods were used. In the theoretical aspect, we used the traditional general scientific methods: analysis and synthesis - to choose and determine the most appropriate directions and forms of partner interaction between a university and a multi-functional inclusive practices site for social adaptation of disabled young people. In the practical aspect, traditional methods: observation, interview, and polling - were used to determine the possible directions and forms of interaction between Penza State Technological University and the disabled residents of the autonomous non-profit organization "Kvartal Lui" during implementation of the inclusion model in the educational process.

Description and application of the general scientific methods (analysis and synthesis) and empirical methods (observation, interview) can be seen in the appropriate scientific and educational-methodological literature. This section presents the questionnaire designed by the authors D. Efimova and A. Lushnikov and the results of its implementation. The questionnaire is devoted to the research of the possibilities for cooperation between Penza State Technological University and the autonomous non-profit organization "Kvartal Lui" for assistance in inclusion, and to revealing the interests of the residents to promote their further development, adaptation, socialization, personal and professional growth. The questionnaire implied anonymity. The polling included 30 people with various disabilities: from locomotor apparatus disorders to some degrees of developmental retardation. Residents and graduates of the autonomous non-profit organization "Kvartal Lui" aged from 18 to 40 years old were interviewed.

\section{Results and discussion}

The research yielded the following factual data.

Answering the question "In which sphere would you like to get the services of a tutor/volunteer - a person from the university to help you?", most of the respondents mentioned the sphere of education and personality development, $65 \%$ each. Also, $40 \%$ of the respondents would like to spend time with a tutor/volunteer. This testifies to one of the most important challenges in the life of people with disabilities - deficit of communication and social isolation. Undoubtedly, the residents and graduates of the autonomous non-profit organization "Kvartal Lui" also need assistance in everyday life and employment. These variants were chosen by $30 \%$ and $20 \%$ of the respondents.

The respondents had opposing opinions about obtaining a university education. $45 \%$ of the respondents answered that they would like to get a higher education. The same number of the disabled do not need a university education, while $10 \%$ could not answer. Thus, about a half of the respondents take a proactive position and, despite health problems, are ready to overcome difficulties, live a full-fledged life and develop in the professional sphere.

We got various answers to the question about the reasons for the lack of desire to study: from bad poor health $(35 \%)$ to the lack of interest $(40 \%)$. To the question about the preferred level of the desired education, most of the respondents $(60 \%)$ marked secondary professional education. $40 \%$ of the residents expressed demand for short-term courses, but $50 \%$ of the residents rejected this type of learning. To the question about the preferred form of education, the residents mainly chose full-time education $-70 \%$ preferred personal contact to distant learning. The maximally preferred type of cooperation with the university 
appeared to be educational cooperation (60\%) followed by professional cooperation $(25 \%)$. When asked about the objects of the future cooperation, most of the respondents $(75 \%)$ mentioned the youth - the university students. To the question about the desire to develop one's personality at a personality development school we obtained the answers that testify that, due to various circumstances, state of health among them, only $45 \%$ of the respondents care about their personality development, while most of the residents worry, first of all, about their physical health.

To the question about the interesting majors we got a wide range of professions, with computer programming and psychology occupying the leading positions. $55 \%$ of the residents and graduates of the autonomous non-profit organization "Kvartal Lui" would like to acquire the profession of a psychologist, $30 \%$ - the profession of a programmer. The profession of an artist/designer and a manicurist are each attractive for 5\% of the respondents. Only $2 \%$ of the respondents are interested in the profession of a craftsman. $3 \%$ of the respondents would like to become an actor, a gamer and an auto mechanic (1\% each, respectively). Such choice of the answers is due to the fact that a psychologist and a programmer can work distantly, via the Internet. An obvious advantage of distant working is the possibility to establish the working schedule depending on the state of health and the necessary medical procedures. Besides, people with limited abilities need comfort and observance of certain requirements to a working place, which can be fulfilled when working online. The professions of a psychologist and a programmer allow improving one's qualification distantly at any educational platform and at any educational establishment, as needed. Such a choice allows the disabled feel themselves full-fledged members of the society, become confident in themselves, and help other people in difficult circumstances.

Having performed a qualitative analysis of the answers, we make a conclusion that the disabled people need support of their personality development - from the inner world to the professional self-implementation. The possible and demanded directions of interaction are educational and cultural-leisure ones. The preferred type of interaction is personal face-toface contact. When rendering support and developing a personal contact, students remain the dominant part. In general, it is obvious that attention, care, kind attitude and assistance on the part of other people are what the disabled need.

The carried out research resulted in the designed program of partner interaction between Penza State Technological University and a multi-functional inclusive practices site for social adaptation of disabled young people (by the example of the autonomous non-profit organization "Kvartal Lui"). The program is of rehabilitation character and includes stageby-stage, systemic and comprehensive implementation during 3 months. He program may be implemented as a pilot one during several days on an open probation site.

The program encompasses two spheres: educational and cultural-leisure ones. Actually, they comprise various aspects of social rehabilitation: social-environmental, socialpsychological, social-pedagogical, socio-cultural, and social-communal adaptation.The methodological basis of the designed program is personality-oriented approach. Psychological-pedagogical support of the young disabled people is implied.

Within the educational sphere of the program, the following practice-oriented courses are implied: "Fundamentals of safe living", "Ecology of health", "Rules and techniques of cooking tasty and healthy food", "Fundamentals of psychology", "Fundamentals of communication", "Fundamentals of computer literacy", "Fundamentals of Photoshop and web-design", "I am a volunteer", "Fundamentals of economics and business". The culturalleisure sphere of the program offers such courses as: "Creativity and youth initiative"; "Decorative and applied arts", "Achievable heights" (organizing sports activities or teaching disabled children to play chess, with the account of their interests and state of 
health); "Photo-mastery"; "Collective music-making" (a technique of integrating young disabled people into the society); "Personality development school".

The courses offered within the spheres of interaction were not selected by chance. The courses' titles and forms of implementation were determined by the results of observations, interviews, and polling of the disabled young people residing in the autonomous non-profit organization "Kvartal Lui", on the one hand, and the spheres of professional training and extracurricular work implemented by Penza State Technological University, on the other. The main forms of the courses implementation are master classes, probation sites, youth initiative sites, competitions, festivals, practical sessions, trainings, pro-seminars, and conferences. During the program implementation, a portfolio is composed for each disabled young person participating in the program and residing in the autonomous non-profit organization "Kvartal Lui".

The program implementation includes several stages. The first stage implies a monitoring of educational and cultural-leisure needs of the disabled young people residing in the autonomous non-profit organization "Kvartal Lui" to involve them into the program and the proposed courses. At the same time, this stage may include correction of the content of the practice-oriented material of the courses to fit the state of health, interests and needs of the disabled young people. At the second stage, the disabled young people are organized to get acquainted with the students and professors who would work with them in the program. The acquaintance takes place while the disabled young people attend a number of events together with the students and professors and watch video films about their activities and results. Such preliminary work excites in the disabled young people social activity and desire to develop relations with students and specialists, preparing them to communicate during the courses. At the third stage, the program is implemented according to the set spheres and designed practice-oriented courses. At the fourth stage, monitoring is carried out to determine the disabled young people's satisfaction with the program.

It should be taken into account that interpretation of inclusion in education has gone beyond the supposition that inclusion refers only to the students with special needs; it refers to all participants of the educational process, students in particular. At that, inclusion in education may encompass not only the organization of interaction within the academic process, but also the social links between learners during breaks, for example, in the format of including into or excluding from self-organized communities [10]. In the course of work, the authors generated an idea which could be useful for practical implementation. The idea is to unite the efforts of various organizations and establishments to render assistance in rehabilitation of the disabled young people. Then their medical, social and professional rehabilitation would be more efficient, providing not only social but also economic effect to the region. Supposedly, if active and interested students of the city united into a single volunteer movement and elaborated a rehabilitation program for inclusive practices organizations and sites in accordance with their majors and future professional activities, that would make the process of restoration of the social status of young people with disabilities more successful and efficient. This idea is in line with the assumption that leadership and the impact of leaders is one of the factors influencing the efficient introduction of inclusion principles into education [11].

\section{Conclusions}

The research resulted in the conclusion that the vector of interaction between a university and specialized platforms engaged in promoting inclusion may lie mainly in the educational sphere. In terms of composition, interaction may be built not only within the frameworks of educational programs in compliance with the Federal State Educational Standards, but also within an extracurricular process. The volume of interaction may be determined 
individually, based on the abilities of the subjects and taking into account the state of health, interests and needs of a disabled person. The authors have designed a program of partner interaction implying its stage-by-stage, systemic and comprehensive implementation in educational and cultural-leisure spheres, encompassing various aspects of social rehabilitation (social-environmental, social-psychological, social-pedagogical, socio-cultural, social-communal adaptation). The forms of the courses implementation are master classes, youth initiative sites, probation sites, practical sessions, trainings, proseminars, and conferences. The program can be complemented with other forms of interaction between a university and an inclusive practices site. It may serve as the basis for a rehabilitation program of assistance to organizations and inclusive practices sites implemented by the students' volunteer movement in the region. In that case, the medical, social and professional rehabilitation of disabled young people would be more efficient, providing both social and economic effect to the region.

\section{Acknowledgements}

The authors thank the Executive Manager of Penza autonomous non-profit organization for facilitating social adaptation of a personality "Kvartal Lui", a public figure, a member of Presidium of the General Council of "Edinaya Rossiya" party, the co-chairperson of the Penza office of the All-Russia People's Front Mariya Lvova-Belova for the opportunity to carry out the research in the above-said non-profit organization.

\section{References}

1. E. Avramidis, B. Norwich, Eur. J. of Spec. Needs Edu., 17(2), 129 (2002)

2. A. Mieghem, K. Verschueren, K. Petry, E. Struyf, Int. J. of Incl. Edu., 24(6), 675 (2020)

3. O. Erten, R. Savage, Int. J. of Incl. Edu., 16(2), 221 (2012)

4. P. Farrell, Int. J. of Incl. Edu., 4(2), 153 (2000)

5. M. Martins, M. Borges, T. Gonçalves, Int. J. of Incl. Edu., 22(5), 527 (2018)

6. T. McMenamin, New Zealand J. of Edu. Studies, 52(1), 109 (2017)

7. T.A. Zamiralova, K.V. Molchanov, A.V. Karpunina, A.A. Kvitkovskaya, A.G. Akhtyan, N.A. Bereza, Acad. J. of Interdisciplinary Studies, 8(2), 261 (2019)

8. A.V. Baharev, Bull. of the Orel State Universit, 4(39), 205 (2014)

9. G. Koutsouris, H. Anglin-Jaffe, L. Stentiford, British J. of Edu. Studies, 68(2), 179 (2020)

10. A. Qvortrup, L. Qvortrup, Int. J. of Incl. Edu., 22(7), 803 (2018)

11. M. Ainscow, A. Sandill, Int. J. of Incl. Edu., 14(4), 401 (2010) 